EPiC Series in Computing
Volume 79, 2021, Pages 150-158
$\begin{aligned} & \text { Proceedings of ISCA 34th International Conference on } \\ & \text { Computer Applications in Industry and Engineering }\end{aligned}$

\title{
An AR-assisted Comparison for the Case Study of the Reconstructed Components in two Old Brick Warehouses
}

\author{
Naai-Jung Shih ${ }^{*}$ and Yu-Chen $\mathrm{Wu}$ \\ National Taiwan University of Science and Technology, Taipei, Taiwan \\ shihnj@mail.ntust.edu.tw, m10913034@mail.ntust.edu.tw
}

\begin{abstract}
The manufacture of brick in Taiwan started since Qing Dynasty. In order to understand the historical context of a city and its industry history, case study was made to two old brick warehouses. This study aims to cross-reference brick warehouses for the evolving application of construction materials and methods, based on the brick joints made on walls or openings. A photogrammetry modeling approach was applied to reconstruct the buildings and details of each warehouse. An AR-based comparison was made on Augmented ${ }^{\mathbb{B}}$ platform using smartphone for on-site and remote comparison. The novelty redefined the connection between process and configuration through a looped interaction between AR and 3D models. The flexibility of smartphone and the portability of cloud-based 3D AR database enabled a former reconstructed result to be remodeled as the reference for follow-up reconstruction process of brick components.
\end{abstract}

Keywords: brick warehouse, augmented reality, reverse engineering, photogrammetry, heritage preservation

\section{Introduction}

One of the best approaches to understand the context of a city is to study industry buildings, which are also historical tangible heritages. Industry buildings were designed to process raw materials, manufacture products, store goods, and exchange resources in Taiwan. Traditional construction details can be found in space layout, style, building materials, and construction method. The application of certain type of building material represents its spatial-temporal background and geographic distribution, under the impact of industry, culture, and technology.

${ }^{*}$ Corresponding author 


\section{Research Purpose}

This study aims to cross-reference two brick warehouses in Taipei to clarify their evolving application of construction materials and methods, based on the brick joints made on walls or openings. The scope was limited to the industrial warehouses made of red bricks, and in the meantime, the constructions were classified as cultural heritage.

\section{Related Studies}

Construction material and method contribute to professional practice that requires design quality to be assessed on field. For old constructions, the heritage building information modeling (HBIM) system may not be well-established and field works are usually required to reconstruct 3D models to facilitate inspection. The reconstruction process and the platform of interaction represent the task and the interface to be conducted and applied to support the fieldwork.

Augmented reality (AR) enables real and virtual information to be interacted in an actual environment in real-time (Abdullah et al., 2017; Ayer et al., 2016; Behzadan \& Kamat, 2013), with user surrounded by real world (Jetter et al., 2018). This virtual content can be created from models originated from the physical world with a highly realistic appearance. In the meantime, users can explore reality with new layers of information using mobile AR applications for a novel interactive and highly dynamic experience (Fritz et al., 2005; Kounavis et al., 2012).

AR applications have been successfully implemented in a broad range of different fields, including navigation, education, industry, medical practice, and landscape architecture (Diao \& Shih, 2019; Wang et al., 2014; Wang et al., 2017; Zhou et al., 2017; Kerr \& Lawson, 2019). Extended reality and informative models have been created for architectural heritage from scans to BIM, virtual reality (VR), and AR (Banfi et al., 2019). HBIM embodies complexity in surveying and preservation (Brumana et al., 2018).

Construction-specific studies were made to the fine details of VR/AR environment to attract attention (Xiao et al., 2018), to simulate the environmental context and spatiotemporal constraints of various processes (Shanbari et al., 2016). Dimensional inconsistencies of building design among participants in VR seem to be partially alleviated through AR by adding a real object that is accurately scaled (Hartless et al., 2020). The advantages of AR to educator can be applied to facilitate knowledge delivery and exploration from learning (Birt \& Cowling, 2017; Joo-Nagata et al., 2017), to locate an object in a represented space (González, 2018), understand cultural aspects (Chang et al., 2019), enhance laboratory learning environments (Frank \& Kapila, 2017), implement a mobile AR system for creative course subjects (Huang, 2019). The operation of 3D objects should be straightforward, and the link between real world objects and digital media should bring a new and beneficial quality for research.

\section{Methodology}

The study started from collecting information in early development of brick industry, red brick warehouse, and cultural heritage in Taiwan. A concept of reverse engineering was applied to reconstruct the buildings and details using photogrammetry modeling applications (Figure 1, left). The images were taken by smartphone, the same device used to interact with 3D AR models. 
An AR-based comparison was conducted on Augmented ${ }^{\circledR}$ platform, with user-friendly interaction made possible to on-site or remote inspections and reconstructions. The analysis and assessment were enabled by the ready-made digit platform originally designed for commercial service. The userfriendly interactive environment was very helpful to clarify the context and the characteristics cross different warehouses for the reactivation of heritage and the preservation of local cultural.

3D models were created by Zephyr ${ }^{\circledR}$, AliceVision Meshroom ${ }^{\circledR}$, or AutoDesk Recap Photo ${ }^{\circledR}$. of Model database was managed in laboratory. The reconstructed models were edited by trimming, decimation, color enhancing, or manifold checking, prior to be exported to cloud-based Augmented ${ }^{\circledR}$ platform (Figure 1, right). The cloud-uploaded models were further checked and edited within the AR platform by the origin location, orientation, surface normal, dimensions, for application feasibility. Each AR model was assigned with a QR-code for easy access from a remote site for situated study by bringing two or more models at the same time for comparison.
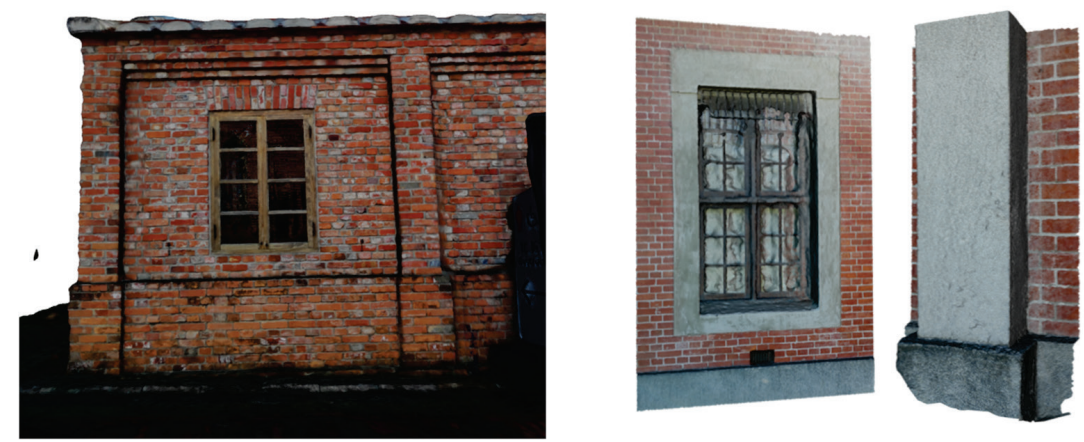

Figure 1: Warehouse with brick details (left) and AR models (right)

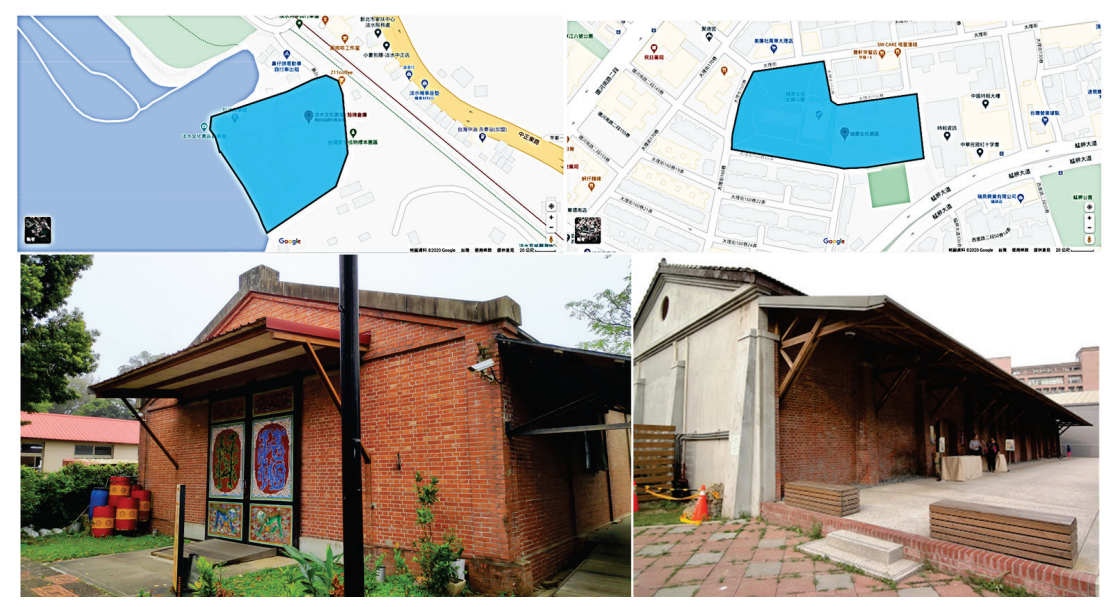

Figure 2: A: Shell House of Stories (left) and B: Taisugar Taipei warehouse (right) in Taipei 


\section{Case Study of Two Warehouses}

The reconstruction experiment was conducted to Shell House of Stories (Figure 2, left) and Taisugar Taipei warehouse (Figure 2, right), by steel plate window on brick wall and arch on brick wall. Both building elements were openings and remodeled to a new inter-relationship with peripheral components of building. Shell House of Stories was located in a warehouse cluster for oil storage. This cluster consisted of buildings in different sizes and locations next to industry facilities and railroad. All buildings were planned and reused in a cultural park for the purpose of preservation and education. This warehouse was purchased in 1897, with new constructions of oil tanks and railroad connecting to Tamsui line for kerosene supply. It was taken over by Japanese during World War II. In 1844 , this warehouse was reused as spared storage space after it caught fire in air raid from allied forces. After WWII, lawsuit of the land property was made between the company and government. In 1997, it was almost demolished under the development of highway. It became a county designated historic site in 2000, and the campus of Tamsui Community College in 2011.

Warehouse A, which stored light oil, was built next to a harbor during Meiji and Taisho era. It's remodeled as Shell House of Stories for community college and the exhibitions of arts and history related to Royal Dutch Shell Plc. Its floor plan measures about $26.3 \mathrm{~m} \times 11.6 \mathrm{~m}$, structured by brick bearing wall of $38 \mathrm{~cm}$ thick. Two layers of brick were cantilevered from the top of wall with $54 \mathrm{~cm}$ high footing on bottom. Buttresses were designed on the exterior side of the wall, instead of interior. Roof was made of two slopes and replaced by corrugated steel sheet.

The test window was located to the north with iron railings and wood window frame. It's covered by steel plate which can be opened and pulled up or down. The door next to it was made of wood panel inside and covered by sliding panel outside. A canopy on north above the corridor was built with wood deck elevated as high as the footing.

Taisugar Taipei Warehouse was part of an old factory, which was scaled down to three warehouses and a railway cargo platform. Open space on peripheral was designed as a historical park accessible by public. Currently this park was closed and the warehouse can only be viewed from outside. Sugar industry prevailed in this area since Quing Dynasty. Most of the industry was private owned. The scale was enlarged intensively during Japanese Colonial Rule. The "Electric Sugar Refinery", which was initiated in Quing Dynasty, was reorganized into "Taipei Sugar Cooperation" in 1911 at current site. The Refinery was merged into the Cooperation in 1916. A railroad branch was constructed to connect to Manga parking space in 1918. The Cooperation was abolished in 1943 due to the shortage of raw material in WWII, and then taken over by Taisugar of government. The warehouse was almost demolished in 1997, and later designated as a historic site in the municipality in 2003, and officially opened to public in 2011.

The original factory in huge planning scale was now reduced to only three warehouses and a railway platform. The warehouse B was made of brick with roof supported by large-spanned wood trusses. Arch and window were also made of brick. Trapezoid-shaped buttresses were only located to the exterior side of the wall. Other than the original brick texture was maintained on south wall, the rest of facades were made of concrete and plaster finish.

The test window was located to the south with original brick texture maintained. AR was applied to compare their details by combining the north window of warehouse A and the background of the arch in the warehouse B on south. Its location and size were adjusted interactively in AR by referring to the brick layout, opening size, and the interval and height of trusses in the ceiling. 


\section{AR Interaction Process}

A two-way virtual and physical interaction was conducted to facilitate the comparison. The concave-convex brick joints on building components like walls or columns present a clear clue of brick type, layout, alignment, and manufacture specification during the inspection process. The joint was further reviewed by color for the ingredient and the approximate year of production.

In additional to the $1^{\text {st }}$ step of visual inspection, photogrammetric modeling and AR interactions were applied to compare details in 3D. The inspection was made interactively using both AR models and physical models, for the joint shaped by the $1^{\text {st }}$ (Figure 3) or $2^{\text {nd }}$ (Figure 4) photogrammetric reconstruction process and the 3D-printed models.
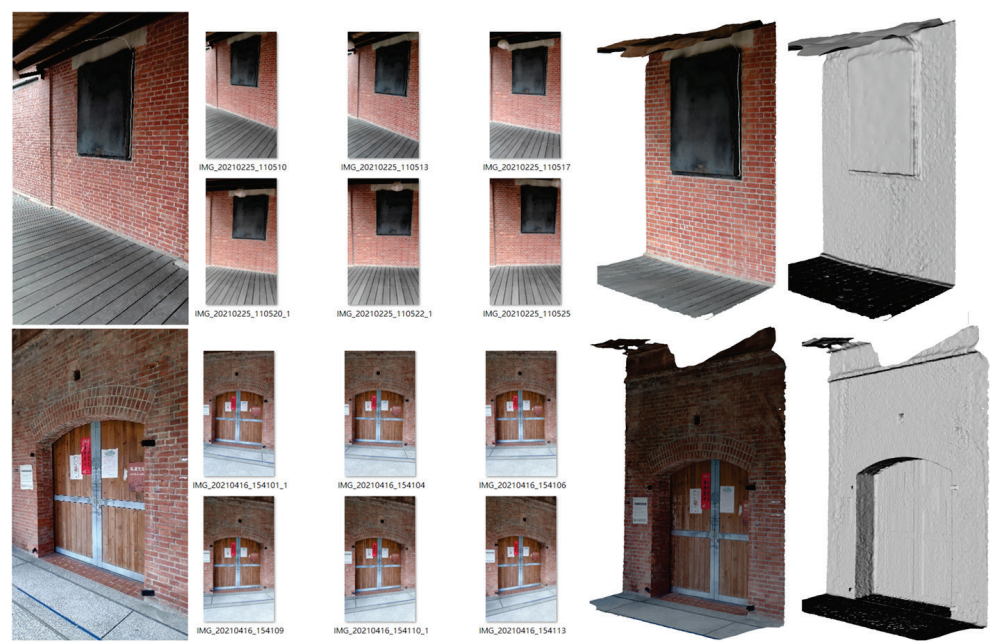

Figure 3: $1^{\text {st }}$ stage of $3 \mathrm{D}$ reconstruction of components

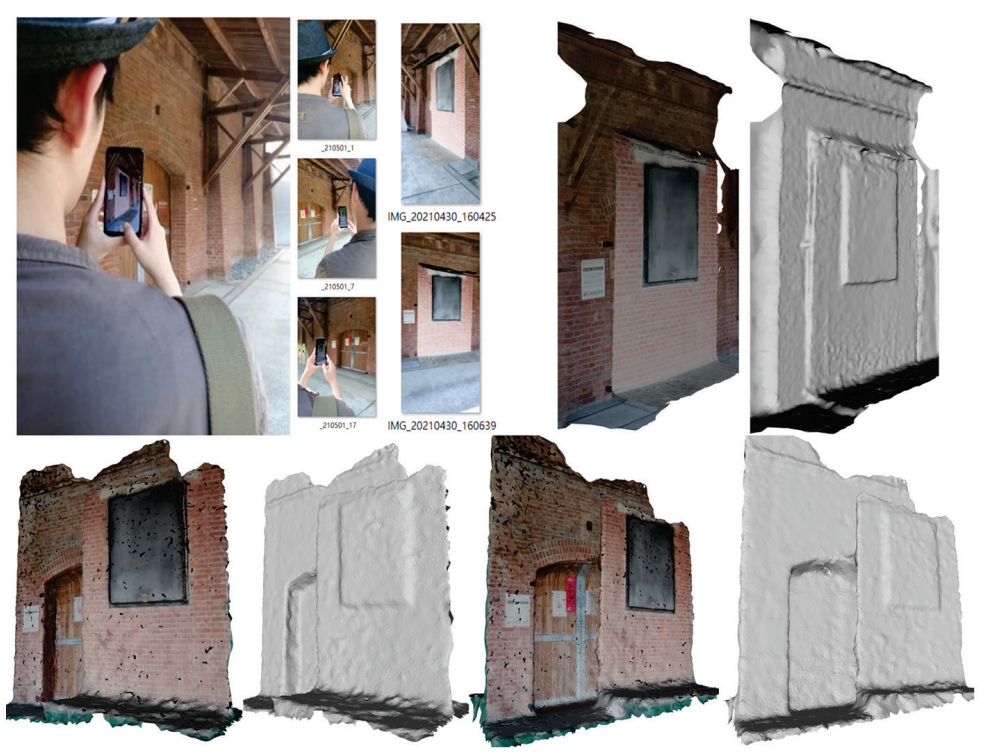

Figure 4: $2^{\text {nd }}$ stage of $3 \mathrm{D}$ reconstruction of the two components in different warehouses 


\section{Novelty}

The novelty of this approach redefined the connection between process and configuration through a looped interaction between $\mathrm{AR}$ and 3D model, for morphology, conservation, and situated comparison. Continuous construction and interaction facilitated a remote confirmation of field job. The reconstruction of the reconstructed situation enabled the verification of AR interacted result, as a measure of AR feasibility in checking layout, conflicts, relative configuration, hidden parts, and interior and exterior correlation. The check by dimensions, recursive reconstructions, and ARreferencing enabled a cross-referencing of evolved construction consistence by manufacturers and methods.

\section{Findings}

The development of historical context and industry development was correlated to clarify the relationship between the construction background and the current situation of the warehouses. The 3D models were integrated with literature and old building drawings to conclude the evolvement of façade and construction technology. An evolving map of the warehouse was made by tracing their distribution progress and pattern, as a record of dynamic process.

The cloud-based AR 3D database was very helpful in situated comparison either on-site or in a laboratory. The flexibility of smartphone and the portability of database enabled a collaboration by sharing AR interaction with remote connection for study assurance. A direction connection was made to the field work of architectural heritage. The database enabled a continuous study in laboratory after the impact of COVID-19 pandemic.

The reconstruction process was helpful to identify the difference between the two components as follows.

1. The color and dimensions of the two types of brick were found different. It's concluded that bricks were made in different batches and ingredients. The offset between the two sets of brick joint increased more as located near the top of wall.

2. The image of the steel plate window was taken on the wood deck about $54 \mathrm{~cm}$ high, about the same height of the foundation in below. When the model was compared in real background, we found the characteristics were located at a relatively low level of elevation and had to be adjusted to match old appearance.

3. The arrangement of building elements was found differently between the distance of eaves and openings. Comparing to the tight connection above window covered by steel plate, the distance was twice higher above the arch, with additional decoration of cantilevered brick molding design added in between.

4. Wood deck and concrete pavement were applied for the two warehouses, as a refurbished and original arrangement of level difference between interior and exterior.

5. Quality of the $2^{\text {nd }}$ reconstructed AR model was deteriorated. Due to the influence of environment lighting, available space, pedestrians, software, the number of acceptable images was reduced significantly and the model quality was reduced consequently. Color difference existed too. Since the $2^{\text {nd }}$ reconstruction was rarely applied as an auxiliary study process, this procedure was found very creative and useful in comparing the difference between subjects by simply bringing two components together. 


\section{Discussion}

Several concerns existed during the reconstruction process, regarding the restriction of lighting and the working space available around the warehouses.

1. Model construction process: Although three applications were applied to reconstruct 3D models of the warehouse and related building components, the model quality was usually determined by software algorithm and the quality and number of images. The performance of computer hardware and software may or may not be another concern, depending if the reconstruction was made by cloud computing or from host computer.

2. Brightness and color difference of images: Due to the influence of environment lighting, the images had to be filtered to exclude the ones with color difference and over/under exposure. Depending on the type of camera or smartphone used to take pictures, it seemed the color of image, which was generated by algorithm, may cause deviation between the configuration of real scene and computer model. Moreover, due to the influence of environment lighting, the images taken with high contrast of brightness were shown on the final model and created uneven appearance of the computer model in a lower quality.

3. AR interference: Drifting problem may occur to the AR model, with unexpected interruption of pedestrian or objects. The drifting may cause problem in confirming the $2^{\text {nd }}$ reconstruction. Clearance also has to be maintained between the subject and the camera, for a proper cropping of the scene.

4. AR field documentation: A set of two researchers was needed to conduct the AR field test and, in the meantime, record field test process. Field space should be sufficient large to allow the operation of the two and to include the scene of the subject, the smartphone screen, and the $1^{\text {st }}$ researcher.

5. The quality of the 2 nd reconstructed models were lower than the ones created in the $1^{\text {st }}$ stage for unexpected fragmentation of the final models. In addition to the alignment problem, the regenerated model should be improved with visual and structural details in higher fidelity.

\section{Conclusion}

Values can be added to the AR process by interaction, composition, confirmation, communication, and recursed operation. The result showed that an evolvement of construction material was closely related to the development of industry. With a close geographic relation to rivers, which supported the transportation and the supply of raw material, the distribution of architectural heritage depicted the historical context upon the evolvement of urban fabrics.

We found that a former reconstructed result can be remodeled as the reference for follow-up reconstruction process, to verify brick components in different types, evolving stages, developing theories or algorithms, and the time of construction. Cross-referencing was made back-and-forth between real and virtual models. As a result, a former reconstruction of heritage model can be applied repetitively for morphological study to enhance situated conservation experience. Under the measure of AR, construction deviations were correlated using a smartphone with specified and interactive operational procedures. 


\section{Acknowledgment}

This research was sponsored by Ministry of Science and Technology of Taiwan. The involved project number is MOST 110-2221-E-011 -051-MY3. The authors express sincere appreciation.

\section{References}

Abdullah, F., M.H.B. Kassim, and A.N.Z. Sanusi. (2017). Go Virtual: Exploring Augmented Reality Application in Representation of Steel Architectural Construction for the Enhancement of Architecture Education. Adv. Sci. Lett., 23 (pp. 804-808). DOI: 10.1166/asl.2017.7449

Ayer, S.K., J.I. Messner, and C.J. Anumba. (2016). Augmented Reality Gaming in Sustainable Design Education. J. Archit. Eng. 22(1) (pp. 04015012-1-04015012-8). DOI:

10.1061/(ASCE)AE.1943-5568.0000195

Behzadan, A.H., and V.R. Kamat. (2013). Enabling Discovery-based Learning in Construction Using Telepresent Augmented Reality. Automation in Construction, 33 (pp. 3-10). DOI: 10.1016/j.autcon.2012.09.003

Jetter, J., J. Eimecke, and A. Rese. (2018). Augmented reality tools for industrial applications: What are potential key performance indicators and who benefits? Comput. Hum. Behav., 87 (pp. 1833).

Fritz, F., A. Susperrgui, and M.T. Linaza. (2005). Enhancing Cultural Tourism Experiences with Augmented Reality Technologies. Proceedings of the 6th International Symposium on Virtual Reality, Archaeology and Cultural Heritage, VAST: 1-6, Pisa, Nov. 8-11.

Kounavis, C.D., A.E. Kasimati, and E.D. Zamani. (2012). Enhancing the Tourism Experience through Mobile Augmented Reality: Challenges and Prospects. International Journal of Engineering Business Management, 4:10. DOI: 10.5772/51644

Diao, P.-H., and N.-J. Shih. (2019). Trends and Research Issues of Augmented Reality Studies in Architectural and Civil Engineering Education - A Review of Academic Journal Publications. Appl. Sci. 9, 1840. DOI: 10.3390/app9091840

Wang, X., M. Truijens, L. Hou, Y. Wang, and Y. Zhou. (2014). Integrating Augmented Reality with Building Information Modeling: Onsite Construction Process Controlling for Liquefied Natural Gas Industry. Automation in Construction, 40 (pp. 96-105). DOI: 10.1016/j.autcon.2013.12.003

Wang, S., M. Parsons, J. Stone-McLean, P. Rogers, S. Boyd, K. Hoover, O. Meruvia-Pastor, M. Gong, and A. Smith. (2017). Augmented Reality as a Telemedicine Platform for Remote Procedural Training. Sensors, 17, 2294. DOI: 10.3390/s17102294

Zhou, Y., H. Luo, and Y. Yang. (2017). Implementation of Augmented Reality for Segment Displacement Inspection during Tunneling Construction. Automation in Construction, 82 (pp. 112121). DOI: 10.1016/j.autcon.2017.02.007

Kerr, J., and G. Lawson. (2019). Augmented Reality in Design Education: Landscape Architecture Studies as AR Experience. International Journal of Art and Design Education. 39(1) (pp. 6-21). DOI: 10.1111/jade.12227

Banfi, F., R. Brumana, and C. Stanga. (2019). Extended reality and informative models for the architectural heritage: from scan-to-BIM process to virtual and augmented reality. Virtual Archaeology Review, 10(21) (pp. 14-30). doi: 10.4995/var.2019.11923.

Brumana, R., S. Della Torre, M. Previtali, L. Barazzetti, L. Cantini, D. Oreni, F. Banfi. (2018). Generative HBIM modelling to embody complexity (LOD, LOG, LOA, LOI): surveying, preservation, 
site intervention-the Basilica di Collemaggio (L'Aquila). Applied Geomatics, 10 (pp. 545-567), https://doi.org/10.1007/s12518-018-0233-3

Xiao, L., W. Yib, H.L. Chia, X. Wang. and A.P.C. Chana. (2018). A critical review of virtual and augmented reality $(V R / A R)$ applications in construction safety. Automation in Construction, 86 (pp. 150-162). https://doi.org/10.1016/j.autcon.2017.11.003

Shanbari, H., N. Blinn, and , R.R.A. Issa. (2016). Using augmented reality video in enhancing masonry and roof component comprehension for construction management students. Engineering, Construction and Architectural Management, 23(6) (pp. 765-781). https://doi.org/10.1108/ECAM-012016-0028

Hartless, J.F., S.K. Ayer., J.S. London, and W. Wu. (2020). Comparison of Building Design Assessment Behaviors of Novices in Augmented and Virtual-Reality Environments. J. Archit. Eng., 26(2), 04020002 (pp. 1-11).

Birt, J. and M. Cowling. (2017). Toward Future 'Mixed Reality' Learning Spaces for STEAM Education. International Journal of Innovation in Science and Mathematics Education, 25(4) (pp. 116).

Joo-Nagata, J., F.M. Abad, J.G.-B. Giner, and F.J. García-Peñalvo. (2017). Augmented reality and pedestrian navigation through its implementation in m-learning and e-learning: Evaluation of an educational program in Chile. Computers \& Education, 111 (pp. 1-17).

doi:10.1016/j.compedu.2017.04.003

González, N.A.A. (2018). Development of spatial skills with virtual reality and augmented Reality. International Journal on Interactive Design and Manufacturing. 12 (pp. 133-144).

Chang, Y.S., Y.-J.R. Hu, and H.-W. Chen. (2019). Learning Performance Assessment for Culture Environment Learning and Custom Experience with an AR Navigation System. Sustainability, 11, 4759. doi:10.3390/su11174759

Frank, J.A. and V. Kapila. (2017). Mixed-reality learning environments: Integrating mobile interfaces with laboratory test-beds. Computers \& Education, 110 (pp. 88-104). http://dx.doi.org/10.1016/j.compedu.2017.02.009

Huang, T. (2019). Seeing creativity in an augmented experiential learning environment. Universal Access in the Information Society, 18 (pp. 301-313). https://doi.org/10.1007/s10209-017-0592-2 